\title{
Comisiones de la Verdad y posibles aprendizajes para el caso colombiano*
}

\section{Truth Commissions and Possible Lessons for the Colombian Case}

\author{
Juanita Andrea Millán Hernández***
}

Recibido: 09/04/2014

Aprobado: 14/07/2015

Disponible en línea: 30/11/2015

\section{Resumen}

Las comisiones de la verdad han sido empleadas como una de las herramientas de la justicia transicional para coadyuvar en el proceso de la verdad, la justicia y la reparación de las víctimas. Las especificidades de diversas formas y modelos de comisiones de la verdad pueden ser de ayuda frente a la posibilidad de tener en Colombia una comisión de la verdad que dé cuenta de los hechos ocurridos en el marco del conflicto armado interno.

\section{Palabras clave}

justicia transicional; derechos humanos; comisiones de la verdad; reconciliación

\section{Abstract}

Truth commissions have been used as one tool of transitional justice to assist the process of truth, justice and reparation for victims. The specificities of different forms and models of truth commissions may help the possibility of having a truth commission in Colombia that helps us account for the events in the context of the internal armed conflict.

\section{Keywords}

transitional justice; human rights; truth commissions; reconciliation

doi:10.11144/Javeriana.papo20-2.cvpa

\footnotetext{
${ }^{*}$ Artículo de reflexión

** Politóloga, Especialista en Resolución de Conflictos y Magíster en Estudios Latinoamericanos de la Pontificia Universidad Javeriana. Actualmente se desempeña como asesora del señor general retirado Enrique Mora Rangel, miembro del equipo negociador del Gobierno colombiano en las conversaciones de paz entre el gobierno de Colombia y la guerrilla de las Farc. Fue Jefe de la Sección de Análisis Prospectivo de la Oficina de Comunicaciones Estratégicas del Comando General de las Fuerzas Militares. Correo electrónico: Juanitamillan77@hotmail.com
} 


\section{Cómo citar este artículo:}

Millán-Hernández, J. A. (2015). Comisiones de la Verdad y posibles aprendizajes para el caso colombiano. Papel Político, 20(2), 425459. http://dx.doi.org/10.11144/Javeriana. papo20-2.cvpa 
Hay que recordar que el tercer inciso del artículo 1 del acto legislativo para la paz, más conocido como Marco Jurídico Para la Paz, reza:

"Una ley deberá crear una comisión de la verdad y definir su objeto, composición, atribuciones y funciones. El mandato de la Comisión podrá incluir la formulación de recomendaciones para la aplicación de los instrumentos de justicia transicional, incluyendo la aplicación de los criterios de selección." (Congreso de la República, 2012)

\section{Introducción}

Este documento analiza siete ejemplos de comisiones de la verdad, cuatro en América ubicadas en Centro y Sur América, y tres en África. Las comisiones analizadas permiten evidenciar grosso modo su evolución a través del tiempo, esto si tenemos en cuenta que se analizan comisiones de la verdad en un lapso de tiempo que va desde 1992 con la comisión de la verdad de El Salvador, pasando por la comisión de la verdad de Sudáfrica 1995, hasta la comisión de la verdad de Ghana en 2002.

De igual forma los casos seleccionados corresponden, cuatro a comisiones de la verdad que se dieron en contextos de conflictos armados que llegaron a su fin (El Salvador, Guatemala, Perú y Sierra Leona), una comisión surgida como parte del tránsito de un régimen de apartheid hacia una democracia de inclusión en el caso de Sudáfrica, y dos comisiones que nacieron como parte del tránsito de regímenes autoritarios (dictaduras en Brasil y Ghana) a regímenes democráticos. El único ejercicio de comisión de la verdad no oficial es el caso de Brasil, a través del proceso Brasil nunca mais.

De otro lado, es importante recordar que en las últimas tres décadas se han creado más de 30 comisiones de la verdad que tienen, en términos generales, la característica de ser organismos de investigación oficiales, temporales, no judiciales, encargados de indagar sobre una constante de abusos contra los derechos humanos, incluidos crímenes contra el derecho internacional, y de determinar la verdad de lo sucedido en determinados contextos. La mayoría de las comisiones concluye su trabajo con un informe final en el que se recogen los resultados de la investigación y se formulan recomendaciones (Amnistía Internacional, 2014).

En síntesis y de acuerdo con lo que recomienda Amnistía Internacional, las comisiones de la verdad deben:

- Esclarecer, en la medida de lo posible, los hechos relativos a las violaciones de derechos humanos ocurridas en el pasado.

- Contribuir con las pruebas reunidas durante sus trabajos al desarrollo de investigaciones y actuaciones penales judiciales que ya estén en marcha y de otras nuevas.

- Formular recomendaciones efectivas para proporcionar una reparación plena a todas las víctimas y a sus familiares. 


\section{Especificidades de las Comisiones de la verdad.}

De acuerdo con Priscila B. Hayner, directora de la Unidad de Desarrollo de políticas del Centro Internacional para la Justicia Transicional en Nueva York, en los últimos treinta años el número y tipo de comisiones de la verdad en todo el mundo ha aumentado significativamente. Se han establecido comisiones de la verdad en cerca de 30 países. Estas presentan características muy variadas pero en general son organismos temporales constituidos para investigar un tipo de violaciones en un periodo de tiempo determinado, producir un informe final y formular recomendaciones de reformas (Hayner, 2006, p. 1).

En términos generales las comisiones de la verdad se establecen por un periodo de tiempo que puede variar entre uno y tres años en promedio y pueden emplear a cientos de personas para recoger testimonios individuales, organizar audiencias públicas y efectuar investigaciones de casos y estudios temáticos. En algunas ocasiones se les atribuye el poder de citación o el derecho a acceder a oficinas y documentos oficiales sin previo aviso. Otras tienen que depender de la cooperación voluntaria, no solo de los funcionarios de alto nivel, sino también de los perpetradores directos, a veces a cambio de promesas de confidencialidad.

Según Hayner las comisiones de la verdad casi siempre reciben información abundante y detallada de las víctimas, los sobrevivientes y otros testigos, logran recoger cientos de declaraciones detalladas. Algunos de estos testimonios pueden presentarse en audiencias públicas, de tal modo que la opinión pública participa en el proceso mucho tiempo antes de que se publique el informe final. No tienen el poder de enjuiciar pero muchas recomiendan la realización de juicios y en algunos casos, han compartido sus archivos con las fiscalías, otras han optado por dar a conocer públicamente los nombres de las personas que según sus investigaciones fueron responsables de violaciones específicas. En estos casos el proceso estándar es permitir a los acusados que respondan a los cargos en su contra, sea por escrito o en entrevistas privadas, antes de que la comisión los nombre en público (Hayner, 2006).

Cada comisión tiene características diferentes, debe tomar en cuenta la realidad y las posibilidades de su entorno particular, contar con la voluntad y el compromiso a nivel nacional para comprender la historia del país y aprender de ella. Las comisiones de las verdad han asumido diferentes formas y características, en términos de su mandato (investigación selectiva vs. comprehensiva), poderes (funciones cuasi judiciales vs. establecer hechos), composición (internacional vs. doméstica) y funciones (reportaje y recomendación publica vs. reintegración de los victimarios a la sociedad) (Rettberg, 2005).

\section{¿Por qué y en qué momento? Condiciones para su establecimiento}

De acuerdo al documento "Instrumentos del Estado de Derecho para sociedades que han salido de un conflicto. Comisiones de la verdad" de la Oficina del Alto Comisionado 
de las Naciones Unidas para los Derechos Humanos (OACNUHD, 2006), la razón principal para establecer una comisión de la verdad se puede encontrar en el derecho que tienen las personas de conocer acerca de lo sucedido a sus familiares desaparecidos o de conocer sobre otro tipo de abusos cometidos en el pasado.

Las comisiones de la verdad tienen la capacidad de acceder a miles de testimonios y evidencias que le facilitan a los países comprender el alcance y las pautas de las violaciones cometidas en el pasado. Según lo que plantea Naciones Unidas en el documento mencionado, se espera que la comisión ayude a una sociedad a comprender y reconocer una historia que se niega o se pone en tela de juicio y con ello, dar a conocer públicamente los testimonios y las historias de las víctimas y ser un método preventivo que evite la repetición de los hechos (OACNUDH, 2006).

Siguiendo con lo que se plantea en el texto "Instrumentos del Estado de Derecho para sociedades que han salido de conflicto. Comisiones de la verdad”, muchos países establecen este tipo de comisiones para fomentar la reconciliación, basados en la idea de que al conocer la mayor cantidad de verdad posible, se generarán procesos de reconciliación. No obstante no debe darse por hecho que la labor de una comisión de la verdad producirá directamente la reconciliación de una comunidad o de un país. Lo anterior se evidencia en la experiencia que demuestra que las comunidades casi siempre necesitan algo más que verdad para perdonar y llegar a una reconciliación. Este suele ser un proceso lento y complejo, y la comisión de la verdad es tan solo una parte. Por tanto cuando se estudia la posibilidad de establecer una comisión de la verdad, deben tenerse en cuenta tres elementos críticos.

Como primera medida, debe existir una voluntad política que permita y aliente activamente una investigación seria sobre los abusos cometidos en el pasado. En segundo lugar, el conflicto violento, la guerra o las prácticas represivas deben haber llegado a su fin. Esto si se entiende que si hay una confrontación armada, es poco probable que se den las condiciones necesarias para llevar a cabo una investigación seria. Y en tercer lugar, debe haber un interés por parte de las víctimas y los testigos en que se realice el proceso de investigación y cooperar con el mismo (OACNUDH, 2006, p. 14).

De otro lado el texto de Naciones Unidas (OACNUDH, 2006) plantea que cuando se estudia la posibilidad de establecer una comisión de la verdad, es preciso tener en cuenta cinco principios o supuestos básicos:

\section{a. Decisión nacional}

No en todos los países o en todas las transiciones es apropiado establecer una comisión de la verdad. La decisión siempre debe corresponder a los ciudadanos del país, sobre la base de un amplio proceso de consultas para recoger las opiniones de las víctimas y los supervivientes y explicar con claridad las funciones, ventajas y limitaciones de 
las comisiones de la verdad. Los agentes internacionales deben proporcionar los datos de comparación y su experiencia, pero deben reconocer desde el principio que el país debe elegir - con toda legitimidad- hacerlo o no. Si decide hacerlo, no debe establecer la comisión inmediatamente al llegar la transición (OACNUDH, 2006).

\section{b. Necesidad de una perspectiva global de la justicia de transición}

Las comisiones de la verdad como ya se ha mencionado, son solo una de las herramientas de la justicia transicional, de manera que estas comisiones no pueden ser la única herramienta para la transición, deben estar acompañadas de otros mecanismos como las reparaciones integrales y administrativas, los procesos de DDR y los instrumentos propios de la justicia ordinaria de acuerdo a la situación de cada país.

\section{c. Modelo único y específico del país}

Cada comisión debe ser única y debe corresponder al contexto nacional, a las oportunidades y condiciones especiales que existan. Si bien es cierto que pueden incorporarse prácticas de otras experiencias, no se deben importar modelos determinados de comisión de la verdad, ya que cada comisión debe basarse en circunstancias locales.

\section{d. Voluntad política e independencia operacional}

Siguiendo con lo que plantea Naciones Unidas, una comisión de la verdad obtendrá los mejores resultados si existe una verdadera voluntad política de que se lleve a cabo una investigación rigurosa y se informe de los hechos. Esto se debe traducir entonces en una efectiva cooperación de las autoridades con la comisión, como por ejemplo que la comisión pueda tener acceso a documentos oficiales.

\section{Apoyo internacional}

La mayoría de las comisiones de la verdad necesitan un apoyo internacional importante para poder cumplir sus mandatos de manera satisfactoria. Esto incluye el apoyo financiero, aunque no exclusivamente, ya que el costo de una comisión puede estar entre los 5 y 10 millones de dólares y los recursos nacionales raras veces son suficientes para cubrir esas necesidades. Sumado a esto, el apoyo internacional se puede concentrar en temas de cooperación técnica y política, por lo general prestada por organizaciones no gubernamentales internacionales e investigadores internacionales.

\section{Establecimiento y funcionamiento de las comisiones de la verdad}

Como primera medida, es fundamental que las comisiones se creen después de un proceso amplio de consultas y de un estudio cuidadoso del tipo de comisión que requiere cada país y cada situación, de acuerdo con las circunstancias específicas de cada caso. En muchas ocasiones las comisiones de la verdad se aprueban de forma 
general en el marco de un proceso de paz, aunque sus características y alcance no se indican de forma detallada.

\section{Mandato}

De otro lado se encuentra el tema del mandato que debe precisar las fechas de inicio y de terminación de los trabajos. Aunque estas deben ser flexibles, el periodo concreto sobre el cual la comisión debe investigar debe quedar explícitamente definido dentro del mandato. Al respecto, el documento de Naciones Unidas (OACNUDH, 2006) plantea que algunas comisiones han examinado infracciones ocurridas durante periodos de tiempo de 35 años, mientras que otras lo hacen con periodos de tiempo mucho más cortos. De manera que para fijar este plazo, según el documento de Naciones Unidas, hay que tener en cuenta aquellos periodos de tiempo en los que se produjeron las infracciones más graves y más numerosas. De igual forma debe escogerse un periodo de tiempo completo y no varios periodos diferentes que se limiten a ciertas fases de la historia del país.

Siguiendo con el documento de Naciones Unidas, el mandato de la comisión debe guardar una proporcionalidad entre la especificidad, la interpretación y la definición. En general se recomienda que el mandato no enumere los incidentes concretos que haya que investigar, sino que describa de forma más general los tipos de infracciones que han de ser investigados.

En este sentido las comisiones de la verdad tradicionalmente han centrado sus investigaciones en los abusos graves de los derechos humanos (torturas, desapariciones, ejecuciones extrajudiciales, crímenes de lesa humanidad, genocidio, entre otros), así como en las infracciones al derecho internacional humanitario y los crímenes de guerra. Según lo investigado por las comisiones de la verdad hasta ahora creadas, la comisión debe dar prioridad a aquellos abusos que la sociedad en conjunto y las victimas en particular consideran especialmente graves y los que necesitan atención más urgente.

El mandato entonces debe enumerar las funciones o actividades fundamentales que la comisión habrá de llevar a cabo. Estás funciones van desde toma de declaración a las víctimas y a testigos, investigaciones y estudios, audiencias o sesiones públicas y todas aquellas actividades que sean necesarias para determinar la verdad en el marco de su mandato (OACNUDH, 2006).

\section{Alcance}

La gran mayoría de comisiones no están facultadas para amnistiar a los autores de delitos. Lo que hacen es recomendar en su informe final que se emprenda una acción penal o una investigación judicial que lleve a posibles procesamientos por los hechos documentados. A menudo entregan las pruebas de las que disponen a las autoridades judiciales.

Siguiendo con lo anterior, vale la pena aclarar que en su calidad de órganos no judiciales, las comisiones propiamente dichas no pueden enjuiciar a nadie, sino que 
deben recurrir al sistema judicial para que lleve adelante cualquier proceso penal. Una comisión de la verdad puede: recomendar el enjuiciamiento, conceder o recomendar la amnistía, este caso solo se ha presentado en Sudáfrica. También puede conceder exención limitada y condicional de responsabilidad penal. En Timor oriental se ha utilizado una variante de este modelo dando amnistía a cambio de verdad, aceptado a nivel nacional e internacional, incluso por las comunidades de víctimas. En este caso la comisión recibió la facultad de anular la responsabilidad penal y civil en delitos no graves, siempre que hubiera reconocimiento o disculpa completos y se prestaran servicios comunitarios o un pago simbólico acordado a la víctima o a la comunidad (OACNUDH, 2006).

\section{Creación y composición}

Las comisiones de la verdad se crean generalmente mediante legislación nacional o por decreto presidencial. De igual forma el mandato según Naciones Unidas debe comprometer al gobierno y al poder legislativo a tener en cuenta las recomendaciones de la comisión. Sin embargo, esto puede plantear dificultades constitucionales o de otro tipo si lo que se percibe es que la comisión está usurpando las atribuciones del parlamento o del poder ejecutivo.

En condiciones ideales, debe estar compuesta por personas ampliamente respetadas por la sociedad, cuya neutralidad sea aceptada por todas las partes de un conflicto previo, o bien el grupo en conjunto, debe ser considerado representativo de un abanico relativamente amplio de opiniones. Las comisiones tendrán más apoyo público e internacional en la medida en que sus miembros sean seleccionados mediante un proceso consultivo y si intenta alcanzar un justo equilibrio en la representación de grupos étnicos, regionales, políticos, religiosos y de diversas opiniones políticas.

\section{Casos: El Salvador, Guatemala, Brasil, Sudáfrica, Sierra Leona, Perú y Ghana}

\section{El Salvador}

La Comisión de la Verdad de El Salvador surgió como resultado de los Acuerdos de Paz entre el gobierno de El Salvador y el movimiento guerrillero Frente Farabundo Martí para la Liberación Nacional, FMLN (1989-1992). El mandato le encargó a la comisión investigar graves hechos de violencia y no enumeró ni identificó ningún caso específico para que fuera investigado por la comisión. Al finalizar su labor presentó un informe con una serie de recomendaciones que incluían: reformas legales, depuraciones en las fuerzas armadas, fuerzas policiales y dentro de la administración pública, así como inhabilitaciones políticas. También recomendó terminar con los grupos ilegales (Escuadrones de la muerte) (Ministerio de Educación, 1994). 


\section{Comisión de la verdad}

$\mathrm{Al}$ respecto, Esteban Cuya plantea que la decisión de crear la comisión de la verdad fue adoptada en los Acuerdos de México firmados el 27 de abril de 1991, en los cuales se definen las funciones y facultades de la comisión. La autoridad de la comisión se amplió con el artículo 5 del Acuerdo de Paz de Chapultepec, titulado "Superación de la impunidad." Estas disposiciones constituyen el mandato de la comisión, definida de la siguiente manera: "La Comisión tendrá a su cargo la investigación de graves hechos de violencia ocurridos desde 1980, cuya huella sobre la sociedad reclama con mayor urgencia el conocimiento público de la verdad" (Cuya, 1996). Para esto, se indicó que la comisión tomaría en cuenta las siguientes consideraciones:

a. La singular trascendencia que pueda atribuirse a los hechos a ser investigados, sus características y repercusión, así como la conmoción social que originaron; y

b. "la necesidad de crear confianza en los cambios positivos que el proceso de paz impulsa y de estimular el tránsito hacia la reconciliación nacional” (Cuya, 1996, p.14)

En cuanto a la impunidad, las funciones específicas que se le asignaron a la comisión se definen de la siguiente manera: "Se reconoce la necesidad de esclarecer y superar todo señalamiento de impunidad de oficiales de la Fuerza Armada, especialmente en casos donde esté comprometido el respeto a los derechos humanos." (Buergenthal \& Figueredo, 1993, p. 20)

De acuerdo con el informe final de la Comisión de la Verdad de El Salvador, además de las facultades que los Acuerdos de Paz le confirieron respecto a la impunidad y la investigación de graves hechos de violencia, también le encargaron elaborar recomendaciones "de orden legal, político o administrativo, que podrán incluir medidas destinadas a prevenir la repetición de tales hechos (de violencia), así como iniciativas orientadas hacia la reconciliación nacional" (Cuya, 1996, p.17).

De esta forma se dotó a la comisión con dos facultades específicas: realizar investigaciones y presentar recomendaciones, en cuya ejecución se comprometieron ambas partes.

En la primera, la misión era investigar hechos graves o flagrantes cometidos por ambos lados del conflicto salvadoreño y no solamente por una de las partes. Y en la segunda, poner atención especial al tema de la impunidad de los hechos de violencia cometidos por oficiales de la Fuerza Armada que nunca fueron investigados ni castigados. Entonces, al optar por investigar un caso en lugar de otro, se tuvieron presentes consideraciones respecto al carácter representativo del caso, la disponibilidad de pruebas, los recursos investigativos disponibles, el tiempo requerido para llevar a cabo una investigación exhaustiva y el tema de la impunidad tal como la define el mandato.

Esta comisión, apoyada por un numeroso grupo de asesores y colaboradores, nacionales y extranjeros, investigó durante seis meses y luego empleó dos meses adicionales 
para elaborar y presentar su informe, titulado "De la Locura a la Esperanza: la guerra de 12 años en El Salvador" (Cuya, 1996, p.18).

Al finalizar su mandato, la Comisión de la Verdad presentó una serie de recomendaciones que incluían entre otras, reformas políticas -depuraciones en las fuerzas armadas, fuerzas policiales - y dentro de la administración pública, inhabilitaciones políticas a las personas involucradas en violaciones de los derechos humanos y del derecho humanitario, por un lapso no menor a diez años.

La división de Derechos Humanos de la ONUSAL le facilitó apoyo técnico y logístico para procurar proteger la identidad de los testigos e informantes, muchos de los cuales solo accedieron a testificar cuando se les aseguró una reserva absoluta. Diversos gobiernos extranjeros y organismos internacionales colaboraron con la comisión suministrando documentos confidenciales emitidos por sus delegaciones diplomáticas y proveyendo declaraciones oficiales de agentes policiales y militares (Cuya, 1996).

\section{Situación del país}

En los Acuerdos de Paz se fijó un calendario de actividades, muchas de las cuales, como la entrega de tierras a los combatientes de ambos lados y la compensación económica, se han cumplido tan solo en parte. En la práctica el Estado salvadoreño descuidó el cumplimiento de los acuerdos. Por eso, pese al empeño del FMLN, así como a los esfuerzos de la ONU y los países amigos, la paz en El Salvador es todavía un proceso muy lento e inconcluso (Amnistía Internacional, 2011).

Como consecuencia del conflicto armado y desde el punto de vista social, el costo de esta guerra ha sido muy alto para El Salvador. La desmovilización de los ex-combatientes y su reinserción a la vida civil han sido una dura labor que aún continúa. Como consecuencia de la guerra, quedaron en manos de la población civil miles de armas de fuego, lo cual propició el surgimiento de pandillas de jóvenes y adultos denominadas maras, dedicadas a la delincuencia y al tráfico de drogas, y que han hecho de El Salvador uno de los países (con ausencia de guerra) más violentos del mundo.

Sin embargo, desde el punto de vista político el país se democratizó. Desde el final de la guerra civil hasta ahora, todas las elecciones realizadas en El Salvador han sido cuidadosamente monitoreadas por la ONU y otros organismos internacionales, a fin de asegurar la transparencia de los comicios.

De acuerdo con el informe de 2011 de Amnistía Internacional sobre el estado de los derechos humanos en el mundo,

La continuación en vigor de la Ley de Amnistía promulgada en 1993 continúa obstaculizando las iniciativas encaminadas a llevar ante la justicia a los responsables de violaciones de derechos humanos cometidas en el pasado. El nuevo gobierno prometió reformar la 
Comisión Interinstitucional de Búsqueda de Niños y Niñas Desaparecidos, creada para determinar el paradero de algunos de los 700 niños y niñas desaparecidos durante el conflicto armado interno (1980-1992). (Amnistía Internacional, 2011, p. 99)

Siguiendo con lo que plantea el informe de Amnistía Internacional, la Corte Suprema de Estados Unidos denegó al coronel Nicolás Carranza, ex viceministro de Defensa salvadoreño, una solicitud de revisión de la declaración de culpabilidad formulada en su contra en 2005. Se le había declarado culpable de crímenes de lesa humanidad perpetrados por unidades de las fuerzas de seguridad que habían estado bajo su control entre 1979 y 1981.

De igual forma, la Audiencia Nacional de España acusó formalmente a catorce soldados y oficiales del ejército salvadoreño de crímenes contra la humanidad y terrorismo de Estado por el homicidio de seis jesuitas, su ama de llaves y la hija de esta última, en noviembre de 1989.

El gobierno manifestó su intención de cumplir los requisitos recogidos en el informe del año 2000 de la Comisión, entre los que figuraban la puesta en marcha de una investigación exhaustiva e independiente sobre el asesinato, reparaciones y la revocación de la Ley de Amnistía de 1993. (Amnistía Internacional, 2011, p. 99)

\section{Guatemala}

Los acuerdos de paz pusieron fin a una guerra de once años en el caso de Guatemala. Hubo varios acuerdos de paz sobre los temas sustantivos del país. Fue un proceso largo que sumó más de diez años y resultó en más de diez acuerdos diferentes como resultado de la negociación entre el gobierno y la Unidad Revolucionaria Nacional Guatemalteca, URNG, que aunque tenía varias facciones, negociaba como un solo actor.

Los acuerdos de paz en Guatemala en su conjunto generan una discusión interesante acerca de los acuerdos minimalistas y los acuerdos maximalistas. En este caso el acuerdo fue global, lo que en cierto sentido llevó a crear expectativas que no se pudieron cumplir después, con lo que se le restó legitimidad al proceso de paz.

\section{Comisión para el Esclarecimiento Histórico (CEH)}

Teniendo en cuenta que el proceso de paz en Guatemala fue bastante largo, existieron distintas rupturas formales y riesgos de ruptura. Durante el proceso de negociaciones hubo muchas crisis políticas, varios intentos de golpes de Estado del ejército, uno de los cuales se concretó - aunque la institucionalidad se restableció a los pocos días-y ofensivas militares de ambos bandos. Sin embargo, una vez que se firma el último acuerdo de paz, el proceso avanza y se produce la desmovilización de la guerrilla (Indepaz, 2007). 
La Comisión para el Esclarecimiento Histórico (CEH) se estableció en los acuerdos de paz de Oslo entre el gobierno de Guatemala y los grupos armados que conformaban la Unidad Revolucionaria Nacional Guatemalteca (URNG). En el acuerdo específico que crea la comisión, se plantea que el pueblo de Guatemala tiene derecho a conocer la verdad sobre las más graves violaciones de los derechos humanos, una formulación ausente en las otras comisiones de la verdad llevadas a cabo hasta el momento (CEH, 1994).

Esta comisión representa un cambio cualitativo en el desarrollo de las comisiones de la verdad, toda vez que además de expandir en profundidad y cobertura el mandato y los poderes de las comisiones, propone explícitamente que la búsqueda de la verdad tiene un valor independiente al proceso judicial, indicando que es posible imaginar un concepto de justicia más amplio que aquel meramente enfocado en la acción judicial (ICTJ, 2011, p. 346).

De acuerdo con Eduardo González, en su artículo “¿Hacia dónde van las comisiones de la verdad?” la CEH se planteó simultáneamente como una institución que no indicaría las responsabilidades de ningún individuo y cuyo informe no tendría consecuencias judiciales. Esta comisión hace énfasis en que sus mecanismos son paralelos e independientes a los judiciales. Según González, la CEH desarrolló su tarea con un enfoque multidisciplinario que combinó la determinación jurídica de los hechos y la valoración de la experiencia de las víctimas, en particular de las comunidades indígenas (González, 2011, p. 346). La CEH tenía como parte de su mandato la recomendación de medidas para preservar la memoria histórica de las víctimas, fomento de una cultura de respeto mutuo y observancia de los $\mathrm{DD}$. $\mathrm{HH}$, no tuvo la facultad de individualizar. Sin embargo, dentro de los hechos documentados se encuentran (González, 2011, p. 346):

- Actos de genocidio por las fuerzas gubernamentales contra el pueblo maya.

- Exterminio, ejecuciones arbitrarias, desapariciones y secuestros de las fuerzas gubernamentales y las guerrillas.

- Actos de violencia de grupos poderosos económicamente, con el apoyo de fuerzas estatales.

- Desplazamientos forzados en masa y reasentamiento militarizado por el Estado.

- Reclutamiento forzado de las guerrillas.

El informe final se denominó Guatemala memoria del silencio y fue publicado en febrero de 1999. En este se evidencia el genocidio contra el pueblo maya. La comisión recibió la denuncia de 42.275 víctimas que incluían asesinatos, desapariciones, torturas y violaciones. El informe establece el número de muertos en 200.00o, dentro de los cuales según el informe, "el Estado fue el responsable del 93\% de los casos y la guerrilla del $3 \%$. Allí se recomendaron cambios institucionales, depuración militar, reparación a las víctimas" (Herrera \& Torres, 2005, p. 91), 


\section{Situación del país}

Después de 17 años de celebrados los acuerdos de paz que pusieron fin a una cruenta guerra civil (1962-1996), Guatemala aún tiene temas pendientes por resolver en materia de atención a los derechos de las víctimas, debido a un incompleto proceso de reparación y a la impunidad de la inmensa mayoría de las violaciones a los derechos humanos producidas en ese contexto. Adicionalmente en los últimos años, la criminalidad organizada con fuertes vínculos con instituciones públicas, ha causado numerosas muertes, lo que conllevó la creación de una comisión internacional respaldada por las Naciones Unidas (ICTJ, 2011).

En Guatemala se han dado grandes avances en los campos económico y social. Se incrementaron significativamente las cifras de escolaridad y de cobertura de salud, se duplicaron los presupuestos de educación y salud, se diseñó una nueva política de vivienda y se pusieron en marcha inversiones económicas muy significativas en lo que habían sido las principales áreas de conflicto para cumplir con el acuerdo del retorno de las poblaciones afectadas por el conflicto armado.

Sin embargo, en el año 2011 la violencia afectó a la mayoría de la población como resultado de la delincuencia común y las pandillas. La delincuencia violenta y la violencia de las pandillas siguieron siendo generalizadas. Según la Procuraduría de los Derechos Humanos de Guatemala, a lo largo del 2010, 5.960 personas perdieron la vida a causa de la delincuencia (Amnistía Internacional, 2011).

Finalmente se encuentra que la mayoría de las violaciones de derechos humanos documentadas que se cometieron durante el conflicto armado interno de 1960-1996 seguían sin resolverse. No se cumplió el compromiso formulado por el presidente en $2008 \mathrm{de}$ desclasificar y hacer públicos todos los archivos militares relacionados con el conflicto.

\section{Brasil}

De acuerdo con el Centro Internacional de Justicia Trasnacional en su capítulo sobre Brasil, este es el único país de la región que no implementó mecanismos oficiales de justicia transicional en el tránsito de la dictadura a la democracia, y donde por el contrario, la adopción de estos mecanismos se ha dado de forma tardía y en medio de la estabilidad democrática (ICTJ, 2010).

\section{Comisión no oficial, Brasil nunca mais}

Hasta 1985 en Brasil no se implementaron mecanismos de justicia transicional como comisiones de la verdad o programas administrativos de reparación oficiales, sin embargo sí existieron iniciativas no oficiales de verdad en el país. Un ejemplo de este tipo de iniciativas fue el informe Brasil: Nunca Mais, reporte elaborado por la Arquidiócesis de Sao Paulo y publicado en 1985 con base en archivos y documentos de las Fuerzas 
Militares. La investigación comenzó en agosto de 1979 y concluyó en marzo de 1985 y tuvo como objetivo conocer las violaciones a los derechos humanos cometidas durante las dictaduras (1964-1979). Las investigaciones fueron dirigidas por miembros de la Arquidiócesis de Sao Pablo.

Según el informe, la tortura fue una práctica extendida durante la dictadura (19641979). El informe presenta además datos históricos sobre el origen de los regímenes militares, el desarrollo de los aparatos represivos y la perversión del derecho penal que favoreció el atropello (ICTJ, 2010). En el período investigado se lograron sistematizar informaciones contenidas en 707 expedientes de procesos llevados ante el Tribunal Militar Supremo. Por esto, una característica del informe es que se basa, fundamentalmente, en documentos oficiales de los procesos judiciales llevados a cabo por los Tribunales militares contra activistas y opositores. (Arquidiócesis de Sao Paulo, 1985)

Después de publicados los volúmenes del informe Brasil Nunca Mais, las fuerzas armadas publicaron un documento como respuesta titulado Brasil Sempre, justificando su acción, llevada a cabo, según ellos, "para salvar a la patria del monstruo del comunismo y del caos interno" (Marchesi, 2001, p 7), el informe Brasil Nunca Mais explícitamente no presenta recomendaciones ni formula peticiones directas para reformas en la policía y el Ejército (Arquidiócesis de Sao Paulo, 1985).

De acuerdo con el Centro Internacional para la Justicia Transicional, durante la dictadura brasilera, entre 1965 y 1985, cerca de 150 personas fueron desaparecidas, más de 100 asesinadas y más de 40.000 fueron víctimas de tortura, detención arbitraria, privación de su actividad laboral y exilio. La Ley de Amnistía de 1979 otorgó perdón a todos aquellos que hubieran cometido crímenes de naturaleza política. En el marco de la transición brasileña (1985), la amnistía fue asumida como un paso para la reintegración de miles de personas perseguidas por motivaciones políticas durante el régimen militar. Sin embargo, los sucesivos gobiernos democráticos y los jueces brasileros asumieron que dicha amnistía beneficiaba también a los agentes del Estado que emplearon la tortura, el asesinato y la desaparición forzada de personas como parte de una estrategia de terror de Estado (ICTJ, 2010).

\section{Situación del país}

Tras 25 años de concluida la dictadura militar (1964-1985), Brasil continúa buscando respuestas para enfrentar el legado de crímenes contra los derechos humanos y lograr verdad, justicia y reparación para las víctimas de la dictadura. De acuerdo con el informe de Amnistía Internacional sobre el estado de los derechos humanos en el mundo del 2010, uno de los puntos recogidos en el plan nacional de derechos humanos era la promesa de crear una comisión de la verdad y la reconciliación de carácter oficial, con el fin de investigar los abusos perpetrados durante el régimen militar (1964-1985). 
Algunas ONG y familiares de víctimas criticaron las propuestas iniciales porque entre las atribuciones de la comisión no figuraba, al parecer, el enjuiciamiento de violaciones de derechos humanos cometidas en el pasado (Amnistía Internacional, 2011).

Aunque en Brasil no ocurrió un conflicto armado interno y el proceso de transición se realizó en medio de la estabilidad democrática, muchas de las causas que buscó repeler la dictadura todavía existen y no han sido solventadas del todo. Sin embargo, Brasil ha sido un claro ejemplo de transición por lo menos en términos políticos, por cuanto los perseguidos del pasado son ahora los líderes del presente.

\section{Sudáfrica}

En el marco de la transición democrática Sudáfrica ha experimentado cambios fundamentales que pueden estudiarse en numerosas facetas. Uno de ellas es la Comisión de la Verdad y la Reconciliación, conocida por sus siglas en inglés como TRC (Truth and Reconciliation Commission). Dicha Comisión forma parte del proceso de transición negociada, donde jugó dos papeles fundamentales: dar respuesta a las demandas de ciertos grupos de la sociedad civil que pedían justicia ante las violaciones a los derechos humanos cometidas durante el apartheid, y ejercer un tipo de justicia que no pusiera en peligro los acuerdos obtenidos entre las principales fuerzas políticas que dieron fin al apartheid. A raíz de estos compromisos se deriva que la TRC presenta características únicas en su tipo, como la realización de audiencias públicas y el otorgamiento de amnistías (Ventura, 2012).

\section{Comisión de la Verdad y la Reconciliación (TRC)}

En este marco, La Comisión de la Verdad y la Reconciliación (TRC) inaugurada en 1995, tuvo como objetivo exponer a la sociedad un retrato tan amplio como fuera posible de las causas, naturaleza y duración de las violaciones a los derechos humanos. En este sentido se dio a la tarea de construir la memoria oficial de la nueva Sudáfrica a partir de la investigación de violaciones a los derechos humanos (asesinato, secuestro, tortura y malos tratos) cometidas desde 1960 hasta 1994 bajo un móvil político. En dicho proceso se dio una constante pugna de intereses, la cual permitió corroborar que en torno al concepto de memoria pueden suscitarse importantes controversias que pueden involucrar el concepto de poder. En el caso específico de la TRC, algunos miembros de los antiguos movimientos de liberación e incluso de los integrantes del viejo régimen trataron de desafiar el trabajo de la comisión (Ventura, 2012).

También fue su misión establecer en qué casos y por qué razones se otorgaría amnistía. La comisión también tendía la misión de restaurar la dignidad humana de las víctimas, reparar los daños económicamente (en los casos en que fuera posible) y recopilar toda la información detallada de los testimonios de las víctimas y perpetradores para evitar la repetición de la historia. 
La TRC estuvo constituida por tres comités distintos: el Comité de Violaciones de los Derechos Humanos -encargado de ver por las víctimas a través de sus propios testimonios y también a través de la investigación legal-, el Comité de Amnistía -que evalúo las solicitudes de amnistía (Truth and Reconciliation Commission of South Africa Report, 2006) - y el Comité de Rehabilitación y Reparación -cuya misión era poner en marcha una política de reparación para restaurar las vidas de las víctimas y sobrevivientes de violaciones graves de derechos humanos-. En muchos casos la reparación fue prácticamente simbólica, la reparación real se ha dado más bien bajo un proyecto de affirmative action y black empowerment, que ha permitido que las razas no-blancas en Sudáfrica tengan además de igualdad de derechos, medios económicos para integrarse tanto a la nueva sociedad democrática como a la economía (Ventura, 2012).

Cada uno de estos elementos permitió que la TRC realizara una codificación de los mismos para transformarlos en un vehículo específico de la memoria, materializado en el reporte de la comisión. A través del estudio de los siete volúmenes que componen el reporte es posible comprender ciertos elementos centrales en la construcción de la nueva memoria oficial sudafricana. Entre ellos destaca la presencia de la religión como un factor importante para vincular el perdón y la reconciliación; la existencia de una nueva categorización pública de las acciones cometidas en el pasado, por medio de la cual expresiones como subversión o el uso de la violencia estatal cobraron un nuevo significado, y la complejidad de investigar hechos del pasado que involucraron al antiguo gobierno y sus instituciones, e incluso a los movimientos de liberación, llamados a responder por sus actos para reforzar el sentido de responsabilidad y justicia del nuevo régimen (Ventura, 2012).

El papel de la TRC durante la transición democrática no solo radicó en la construcción de los cimientos de la memoria oficial de la nueva Sudáfrica. Su labor incluyó también la elaboración de una serie de recomendaciones necesarias para garantizar cambios reales que percibiera la población sudafricana. Las audiencias de la comisión duraron poco más de dos años. La Comisión recibió 21.296 declaraciones provenientes de víctimas y 7.127 solicitudes de amnistía. Si fue un éxito o un fracaso, sigue siendo tema de debate en Sudáfrica y en el mundo entero, pero una cosa sí es cierta: el público en general aprendió que la relación entre verdad y reconciliación es mucho más compleja de lo que aparenta. (Truth and Reconciliation Commission of South Africa, 2006).

Se presentó un primer reporte ante el presidente Mandela en octubre de 1998. El reporte final, publicado en 2002, contenía 250 recomendaciones. Entre ellas, una política substancial de reparación que preveía indemnizaciones financieras para cada una de las víctimas, así como la edificación de monumentos públicos conmemorando el sufrimiento de las víctimas. 


\section{Situación del país}

El trabajo de la TRC concluyó oficialmente el 31 de diciembre de 2001 en virtud de una proclamación presidencial que data de mayo de 2001. La responsabilidad legal de sus actividades restantes fue transferida al Ministerio de Justicia. Sin embargo, los antiguos miembros y empleados de la TRC continuaron la redacción de los últimos dos volúmenes con el fin de completar el reporte de actividades, enfocándose en los trabajos de la comisión de amnistía y en establecer la lista de las víctimas elegibles a reparaciones. Esta tarea fue terminada en marzo de 2003, fecha en la cual la TRC fue disuelta después de seis años y medio de actividades (ICTJ, 2011).

En términos generales, es impactante constatar que el reporte final de la TRC y sus recomendaciones no fue recibido con mucho apoyo político. De las más de 90.000 personas que presentaron una queja ante la Comisión de la Verdad y de la Reconciliación, solo 22.000 fueron reconocidas como víctimas con derecho a reparaciones. Hoy muchas de ellas han formado un grupo de apoyo conocido con el nombre de Khulumani.

\section{Sierra Leona}

El conflicto armado en Sierra Leona ha sido uno de los más violentos de la década de 1990 en el que se cometieron grandes violaciones de los derechos humanos. La causa principal del conflicto radicó en los diamantes y su tráfico ilegal, que sirvieron para financiar al Frente Revolucionario Unido (FRU). El país ha tenido cinco elecciones generales y sufrido cinco golpes de Estado desde su independencia, mezcla de mal gobierno, conculcación de los derechos humanos fundamentales, despilfarro, mala gestión económica y exclusión social (Escuela de paz de Barcelona, 2001).

En junio de 1999 se firmó el acuerdo de Lome que creó la Comisión de la Verdad y posteriormente el acuerdo de alto al fuego, que permitió el inicio de la transición hacia el fin del conflicto, establecido el 18 de enero 2002. Lo anterior facilita el levantamiento del estado de emergencia y el comienzo de la campaña electoral para la celebración de elecciones el 14 de mayo de 2002 (Escuela de paz de Barcelona, 2001).

\section{Comisión de la Verdad}

La concesión de una amnistía general al finalizar el conflicto fue altamente criticada por Naciones Unidas, que dijo que no reconocería la amnistía para responsables de genocidio, crímenes contra la humanidad, crímenes de guerra y otras violaciones graves del Derecho Internacional Humanitario. El 14 de agosto del 2000 el Consejo de Seguridad de Naciones Unidas decidió por medio de la resolución 1315, crear un tribunal especial independiente en Sierra Leona para perseguir a los máximos responsables de violaciones graves del Derecho Internacional (Escuela de paz de Barcelona, 2006). 
Como resultado de los acuerdos de paz se contempló crear una comisión de la verdad cuya función era hacer frente a la impunidad, romper el ciclo de violencia, proporcionar un foro para que víctimas y victimarios narraran su historia y facilitar de ese modo la curación y la reconciliación. Con el espíritu de alcanzar la reconciliación nacional, la Comisión se ocupó de las violaciones de derechos humanos perpetradas desde el inicio del conflicto en 1991 y recomendó las medidas a tomar para la rehabilitación de las víctimas. La comisión fue conformada por una muestra representativa de la sociedad sierraleonesa con la participación y el apoyo técnico de la comunidad internacional (Escuela de paz de Barcelona, 2006).

El informe final fue entregado al presidente de Sierra Leona el 5 de octubre de 2004 y presentado al Consejo de Seguridad de las Naciones Unidas el 27 de octubre 2004. La comisión encontró que la causa fundamental de la guerra fue la corrupción, el conflicto por los recursos naturales y un control abrumador del poder ejecutivo. El colonialismo y la subversión de los sistemas tradicionales también tuvieron un efecto (United States Institute of Peace, 2002b).

En un documento sobre la comisión de la verdad de Sierra Leona, el Instituto de Paz de los Estados Unidos (United States Institute of Peace, 2002b) planteó que las violaciones a los Derechos Humanos más comunes fueron desplazamientos forzados, secuestros, detenciones arbitrarias y asesinatos, saqueos y pillajes. La dirección del FRU, el CRFA, el Ejército de Sierra Leona (SLA) y la Fuerza de Defensa Civil (CDF) fueron los responsables de violaciones de derechos humanos contra la población civil.

Las principales recomendaciones de la comisión se refieren a la lucha contra la corrupción, la creación de un nuevo proyecto de ley de Derechos desarrollado en un proceso participativo constitucional, la independencia del poder judicial, el fortalecimiento del papel del Parlamento, un control más estricto sobre las fuerzas de seguridad, la descentralización y la autonomía económica reforzada para las provincias; así como el compromiso del gobierno de entregar los servicios públicos básicos y la inclusión de los jóvenes y las mujeres en la toma de decisiones políticas. La comisión recomendó el establecimiento de un programa de reparaciones y un organismo de ejecución, como se había sugerido ya en el Acuerdo de Lomé (United States Institute of Peace, 2002b, p. 1).

El 26 de agosto del 2004 se creó la Comisión de Derechos Humanos con el mandato de supervisar el cumplimiento de las obligaciones incluidas en los tratados, promover la conformidad con las leyes nacionales e internacionales y facilitar la puesta en marcha de las recomendaciones de la Comisión para la Verdad y la Reconciliación. En noviembre de 2007, las Naciones Unidas y la Comisión de Derechos Humanos de Sierra Leona instaron al Gobierno a elaborar una estrategia de conclusión para la aplicación de las recomendaciones de la CVR sin más demora. La Comisión para la Verdad y la Reconciliación coexistió con el Tribunal Especial para Sierra Leona, que tenía que tratar los 
casos de "los que tienen la mayor responsabilidad" por los crímenes internacionales cometidos durante el conflicto (United States Institute of Peace, 2002b, p. 1).

La Comisión Nacional para la Acción Social (NACSA) fue designada por el gobierno para poner en práctica las recomendaciones de la Comisión de Verdad y Reconciliación. A partir de agosto de 2008 el gobierno de Sierra Leona y las Naciones Unidas pusieron en práctica un proyecto de un año dirigido a fortalecer la capacidad institucional para implementar las recomendaciones de la comisión relativas a las reparaciones.

Según el Instituto de paz de los Estados Unidos, este proyecto recibió \$3 millones de dólares del Fondo de Consolidación de la Paz de las Naciones Unidas. Un total de 29.733 víctimas han sido registradas. A principios de 2010, los amputados, heridos de guerra y las víctimas de violencia sexual recibieron un pago provisional de \$100 USD. El NACSA ha empezado a aplicar otras medidas de reparación tales como apoyo a la educación y la salud, y para el 2009, el gobierno puso en marcha el Fondo de Víctimas Fiduciario previsto en el Acuerdo de Paz de Lomé de 1999 y la Ley de TRC de 2000.

Human Rights Watch denunció el uso generalizado y sistemático de la violación y otros tipos de violencia sexual contra miles de mujeres y niñas durante los diez años de conflicto armado por parte de miembros de los grupos armados de oposición, pero también por las FFAA y miembros de las fuerzas de mantenimiento de la paz (Escuela de paz de Barcelona, 2003).

\section{Situación del país}

El conflicto civil de 1991 concluyó con un acuerdo de paz firmado en 1999, conseguido gracias al apoyo de las Naciones Unidas para el mantenimiento de la paz y una declaración oficial de paz en enero de 2002 (AIF, 2007).

La guerra civil de Sierra Leona destruyó infraestructura, empresas y la trama básica de la sociedad. Hacia el final de la guerra, el ciudadano común sobrevivía con el equivalente de 38 centavos de dólar al día y dos millones de personas, es decir casi un tercio de la población, habían sido desplazadas. Tras el cese al fuego, el sólido desempeño macroeconómico dio paso a una fuerte recuperación económica. Como sucede a menudo cuando los países emergen de la devastación de una guerra civil, el ingreso aumentó considerablemente, en este caso, a un promedio anual de US\$220 por persona para el 2005 (AIF, 2007).

\section{Perú}

En el Perú se han creado distintas comisiones para investigar los hechos de violación de derechos humanos como consecuencia del conflicto armado entre el gobierno y el grupo guerrillero Sendero Luminoso. Está aquella por ejemplo, establecida para investigar el asesinato de ocho periodistas y un guía campesino el 26 de enero de 1983 en la localidad de Uchuraccay, Ayacucho. O aquella dada para esclarecer la masacre de más 
de 250 prisioneros políticos en dos cárceles peruanas el 18 y 19 de junio de 1986, perpetrada por parte de efectivos de la Guardia Republicana y de la Marina de Guerra del Perú. Y la más reciente, para esclarecer las violaciones de los derechos humanos llamada la Comisión de la Verdad y la Reconciliación, CVR, del 4 de junio de 2001.

\section{Comisión de la Verdad y la Reconciliación, CVR}

La CVR se inauguró el 13 de julio de 2001, inicialmente estaba encargada de investigar las violaciones de derechos humanos durante el gobierno de Alberto Fujimori, pero por presión de la sociedad civil, amplió su mandato para investigar los hechos violentos de las dos décadas pasadas (1980-2000) (Restrepo, 2004). Sus objetivos eran:

[...] analizar el contexto y las condiciones que llevaron al conflicto y las actitudes que generaron violencia, esclarecer los crímenes y violaciones de los DDHH, colaborar en la búsqueda de las víctimas, su identificación y situación, así como adjudicar responsabilidades a los causantes para más adelante recomendar y formular propuestas para reparación y prevención. (Townsend, 2008, p. 37)

Para esto se le dio un plazo de 19 meses y una ampliación de 5 meses en caso de que fuese necesario, para presentar un informe final al presidente de la República y a todo el pueblo peruano. Este proceso es bastante sui generis en Latinoamérica, ya que Perú presentó un conflicto armado interno, pero su resolución no se dio por negociaciones de paz y el comienzo de su proceso transicional no obedece a un cambio de régimen.

La Comisión concluyó que muchos de los hechos que se presentaron en el período analizado (1990-2000) no fueron hechos aislados sino prácticas sistemáticas o generalizadas. En ese orden de ideas, la CVR sistematizó una serie de conductas que catalogó como crímenes de lesa humanidad, y construyó una lista de once tipos de hechos graves: desaparición forzada de personas, ejecuciones arbitrarias, asesinatos, secuestros, torturas y tratos crueles inhumanos o degradantes, violencia sexual contra la mujer, violencia contra menores, desplazamiento interno y violación de derechos colectivos, detenciones arbitrarias y abusos en la administración de justicia (Restrepo, 2004).

Dicha sistematización permitió en primer lugar, condensar y clasificar los testimonios prestados por 16.985 personas en Perú, y en segundo lugar, tener una visión global que posibilitó extraer conclusiones jurídicas sobre lo sucedido e identificar presuntas responsabilidades ${ }^{1}$. El grupo Sendero Luminoso (SL) efectuó asesinatos selectivos

\footnotetext{
${ }^{1}$ Las estadísticas utilizadas en este trabajo han sido extraídas del informe final de la Comisión de la Verdad y la Reconciliación del Perú. Dicho material se encuentra disponible en Comisión de la Verdad y la Reconciliación del Perú. (2003).
} 
y masacres con el propósito de atemorizar y aterrorizar a individuos y a colectivos, desalentar la resistencia y castigar a los insumisos. 11.021 personas asesinadas fueron reportadas a la CVR. En cuanto a desaparición forzada, SL ha sido señalado como responsable de 1.543 casos. Es así como a SL se le atribuye 54\% de los casos de muertos y desaparecidos reportados, constituyéndose como el principal responsable de víctimas fatales del conflicto armado interno del Perú (Hayner, 2006).

El uso generalizado y sistemático del asesinato para eliminar a los representantes del viejo Estado fue propiciado por el dogmatismo y fundamentalismo del pensamiento Gonzalo. En cuanto a las masacres, se reportaron al menos 215 a manos del SL. También se dio cuenta del desplazamiento forzado y la esclavitud de poblaciones asháninkas de la selva central.

Según el informe de la comisión, la desaparición forzada se incrementó a partir de 1983, cuando las Fuerzas Armadas reemplazaron a la Policía en las tareas de control del orden interno y combate a la subversión en el departamento de Ayacucho (Comisión de la Verdad y la Reconciliación del Perú, 2003). Esta se sistematizó entre 1989 y 1993, haciendo que el Perú ocupara el primer lugar en el mundo entre los países en los que se perpetraba la desaparición forzada de personas. Vale la pena resaltar en este sentido la participación de las Rondas Campesinas, a quienes se les atribuye como parte de la estrategia contrasubversiva y como resultado de operativos combinados con las demás fuerzas estatales, un porcentaje considerable de desapariciones (53\%) (Comisión de la Verdad y la Reconciliación del Perú, 2003).

La Comisión que concluyó su mandato en agosto de 2003, ha sido la más completa sobre la investigación de los años de violencia que sufrió Perú. Sin embargo, la CVR tuvo una política de comunicación débil y no logró esclarecer adecuadamente a la población sus finalidades y actividades (Comisión de la Verdad y la Reconciliación del Perú, 2003). Asimismo, la estrategia de difusión de los resultados del informe final a la población quedó poco especificada en las recomendaciones y esta misma fue asignada a un grupo de trabajo multisectorial.

Dentro de estos parámetros en el Perú, la CVR aplicó la teoría que otorga la responsabilidad criminal a la cabeza de la organización entre la cual fue realizado el acto, es decir, al ser la mayoría de delitos casos que ocurrieron al interior de organizaciones, el mando más alto es aquel al que se le otorga la culpa. Como consecuencia de esto existen solamente 47 casos investigados por la CVR, entre los cuales se encontraba la del ex presidente Fujimori. (De Gamboa \& Mejía, 2010)

Él fue encontrado culpable en el 2009 de dos matanzas en los años 1991 y 1992 y por la cual aún cumple una condena de 25 años de cárcel. 


\section{Situación del país}

La situación que se vivió en Perú durante veinte años de confrontación armada demostró que en nombre de una ideología totalitaria y demencial, pequeños grupos se alzaron en armas y declararon la guerra a toda la sociedad peruana. Al estudiar el caso peruano, se hace evidente que tanto el Partido Comunista Peruano como el grupo guerrillero Sendero Luminoso fueron quienes iniciaron el conflicto y constituyen los principales responsables del crecido número de víctimas. No obstante, también vale la pena aclarar que la CVR argumenta que la respuesta del Estado a esta guerra irracional también tuvo comportamientos censurables que ocasionaron dolor y heridas a miles de peruanos.

La transición peruana inicia luego de la renuncia y fuga del ex presidente Alberto Fujimori y la atenuación del conflicto armado desatado por Sendero Luminoso y respondido por agentes del Estado. La Comisión de la Verdad y Reconciliación (2001-2003) estableció que alrededor de 69.00o peruanos habían muerto o desaparecido por acción de los grupos subversivos o de las fuerzas armadas y policiales.

Según Amnistía Internacional, para el 2011 no se registraron avances en la aplicación de las recomendaciones de la CVR. Se produjeron pocos avances en el millar de casos presentados desde 2003 ante la Fiscalía de la Nación en relación con violaciones de derechos humanos cometidas en el pasado (Amnistía Internacional, 2011).

\section{Ghana}

Desde su independencia en 1957, Ghana ha experimentado cinco golpes de Estado y sucesivos regímenes militares, violaciones de derechos humanos ocurridas en cada uno de los gobiernos militares e intensificadas después de los dos golpes de Estado iniciados por el ex presidente J. J. Rawlings en 1979 y 1982. El respeto por los derechos humanos mejoró durante los períodos intermedios de gobierno civil, sin embargo, las administraciones civiles duraron muy poco para poder contrarrestar la cultura de la impunidad y la falta de respeto por el imperio de la ley que se había convertido en la constante en los gobiernos anteriores. No obstante, los gobiernos civiles también abusaron de sus poderes como consecuencia directa de esta historia (Ndemole, 2008).

\section{Comisión de Reconciliación Nacional}

La Comisión de Reconciliación Nacional fue creada por la ley No 611 de enero de 2002, trabajó desde el 14 de enero 2003 hasta el 14 de octubre 2004 y como mandato tenía promover la reconciliación nacional entre los ghaneses, establecer "un registro histórico preciso y completo" de violaciones de derechos humanos y los abusos relacionados con el asesinato, secuestro, desaparición, detención, tortura, malos tratos e incautaciones de propiedad durante tres períodos de gobierno inconstitucionales entre el 6 de marzo 1957 y el 6 de enero de 1993 (United States Institute of Peace, 2002a). 
Cualquier persona podía solicitar que la comisión investigara asuntos específicos dentro de su mandato. Esta también estaba facultada para hacer recomendaciones para la reparación de las víctimas y la reforma institucional. La Comisión terminó su informe final en octubre de 2004 y este se hizo público en abril de 2005. La comisión escuchó el testimonio de 2.129 víctimas y 79 presuntos responsables. El ex presidente, John Jerry Rawlings y el ex asesor de Seguridad Nacional, el capitán KojoTsikata, también testificaron. Se convocaron más de 2.00o audiencias públicas (United States Institute of Peace, 2002a).

En su informe la comisión señaló que el período de gobierno colonial contribuyó al legado de abusos contra los derechos humanos. También concluyó que las instituciones policiales y las fuerzas armadas fueron responsables del mayor porcentaje de abusos. Recomendó un programa de reparación integral con disculpas, un monumento y la compensación monetaria. La cantidad pagada a las víctimas debía basarse en el tipo de violaciones sufridas. En este sentido la comisión sugirió la reparación de 3.000 víctimas de la represión bajo el régimen de Rawlings. De igual forma recomendó reformas dentro de las prisiones, la policía y las fuerzas militares (United States Institute of Peace, 2002a, p. 2).

En el 2006 el gobierno inició un programa de reparaciones en el que un comité de reparaciones debía garantizar el cumplimiento de las recomendaciones de la comisión. En el 2008 Ghana estaba tomando medidas para reformar su sistema judicial y así luchar contra la corrupción en el sector público, sin embargo, la brutalidad policial iba en aumento y los procedimientos del sistema de justicia eran muy lentos.

\section{Situación actual}

Ghana ha experimentado notables mejoras en la situación de los derechos humanos desde 1992. Sin embargo, cuestiones problemáticas continúan presentes que requieren una actuación inmediata, como la violencia contra las mujeres, la pena de muerte y la justicia procesal. A propósito de este tema en el 2009, Amnistía Internacional público un informe titulado Seven point human rights agenda for the new government, en el cual la organización destacaba diversos asuntos que necesitaban mejorar en el país. En el informe la organización recomendaba incluir los siguientes temas:

Cumplimiento pleno de las obligaciones y compromisos regionales e internacionales de Ghana en materia de derechos humanos expuestos explícitamente en los tratados que ha ratificado, abolición de la pena de muerte, adopción de medidas para poner fin a la detención ilegal y garantizar la celebración de juicios justos y sin demora conforme a las normas y tratados internacionales en materia de derechos humanos, reducción significativa de la grave superpoblación de las prisiones y otros centros de detención de Ghana, erradicación de la violencia contra las mujeres, adopción de medidas para detener y prevenir la práctica 
de los desalojos forzosos, protección efectiva contra la denominada violencia colectiva (Amnistía Internacional, 2009, pp. 1-6).

\section{Análisis comparado de las experiencias}

Eduardo González Cueva refiere que las primeras comisiones de la verdad surgidas en América Latina (Argentina 1983 y Chile 1990), se crearon como parte de una respuesta creativa a demandas sustantivas de justicia que no podían satisfacerse con los procedimientos normales de los sistemas judiciales. En ese momento las comisiones no negaban el derecho de las víctimas a obtener un remedio efectivo, pero asumían tácitamente que las instituciones judiciales serían incapaces de proveer tal remedio (Gónzalez, 2011).

Las comisiones iniciales se enfocaron en investigar aquellos hechos que sus creadores, interpretando la opinión pública, consideraban más urgentes o bien más factibles de ser efectivamente investigados. Estas se crearon como grupos especializados a los que se confiaba el descubrimiento de los hechos para luego diseminarlos a través de informes escritos. Ni los mandatos ni la práctica de las primeras comisiones latinoamericanas evidencian un interés específico en crear alianzas o formas de comunicación entre los comisionados y la sociedad civil (ICTJ, 2011).

La comisión de El Salvador surgida en 1991, fue una propuesta que integraba la necesidad de un pragmatismo político y el hecho de que la justicia ordinaria sería insuficiente. De manera que, las partes en conflicto decidieron no abordar en sus negociaciones el tema de la justicia transicional y por el contrario decidieron crear la comisión de la verdad como una herramienta para establecer los hechos acerca de las acusaciones mutuas que se habían lanzado durante la guerra. Tanto la comisión de la verdad salvadoreña como la de Chile, se propuso como un instrumento para establecer los hechos sin perjuicio de las obligaciones legales del Estado, pero con la celeridad que las cortes de justicia serían incapaces de lograr (González, 2011).

Volviendo a lo que plantea Eduardo González, los modelos iniciales de comisiones sufrieron un salto de calidad significativo con la creación a mediados de los años noventa de las comisiones de Guatemala y Sudáfrica. Ambas representan un cambio cualitativo porque además de expandir en profundidad y cobertura el mandato y los poderes de las comisiones, proponen explícitamente que la búsqueda de la verdad tiene un valor independiente al del proceso judicial, indicando que es posible imaginar un concepto de justicia más amplio que aquel meramente enfocado en la acción judicial (ICTJ, 2011).

En el caso de la comisión guatemalteca, pese a que el texto del acuerdo de las que funda la $\mathrm{CEH}$ es sucinto, su formulación permitía una amplia interpretación, pues se enfocaba en todos los hechos que hubieran causado sufrimiento a la población, lo que permitía incluir una gran cantidad de violaciones y hechos a investigar. 


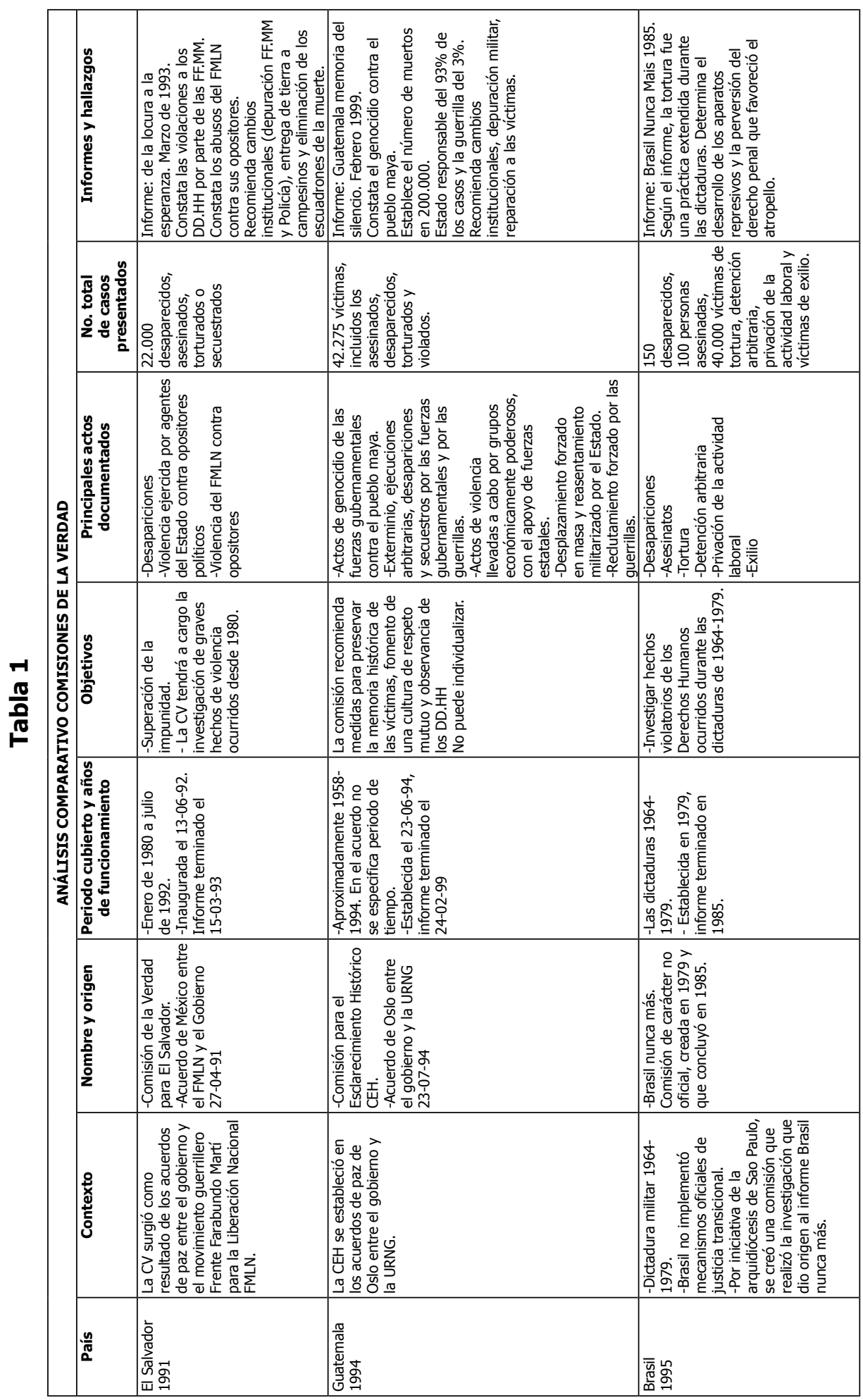




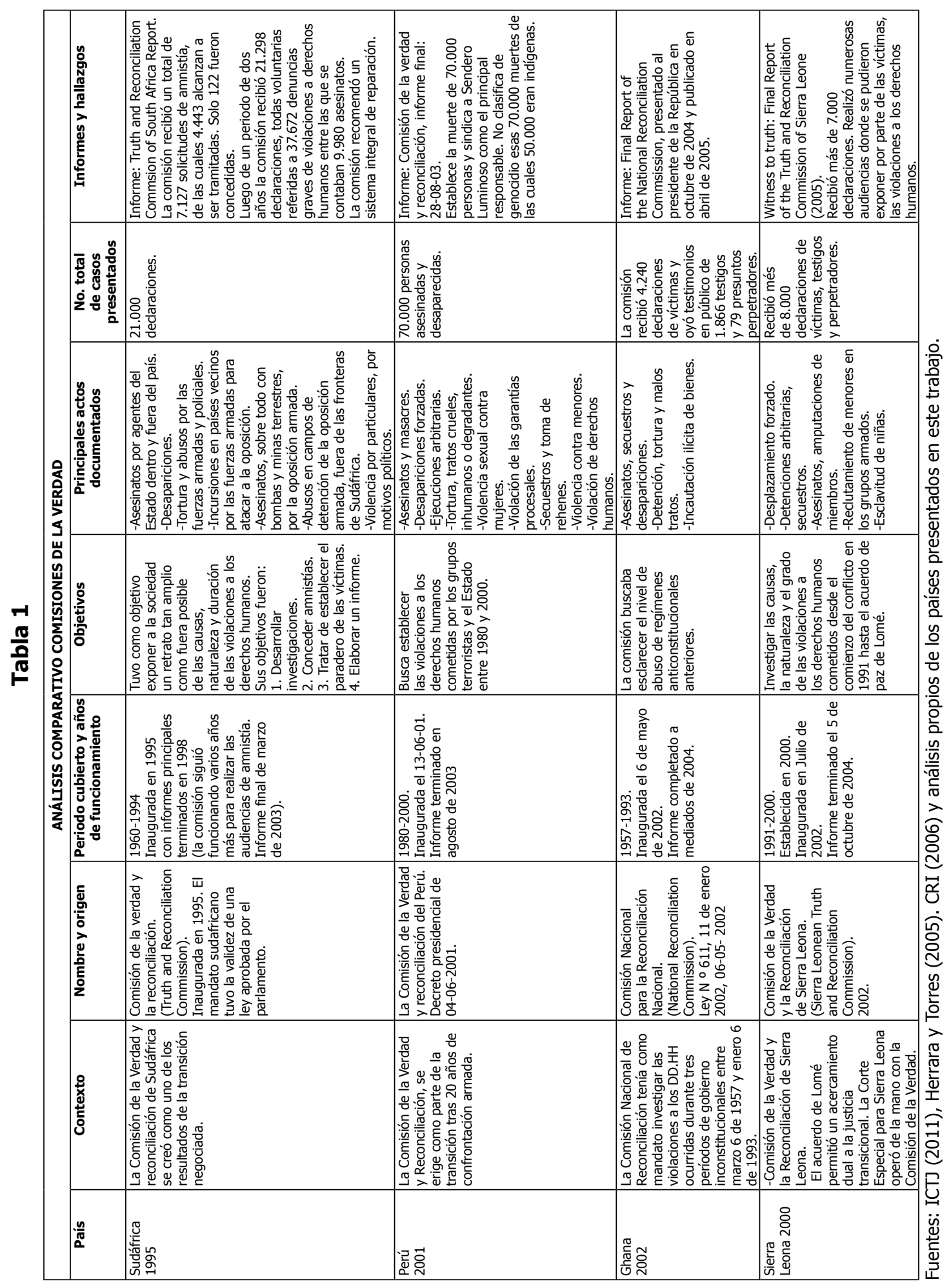


Tabla 2

\begin{tabular}{|c|c|c|c|c|c|c|c|c|c|}
\hline \multicolumn{10}{|c|}{$\begin{array}{c}\text { VIOLACIONES A LOS DERECHOS HUMANOS OBSERVADAS } \\
\text { POR LAS COMISIONES DE LA VERDAD }\end{array}$} \\
\hline & 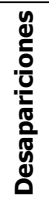 & 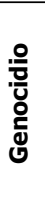 & $\begin{array}{l}\text { 돌 } \\
\text { ț } \\
\text { to }\end{array}$ & 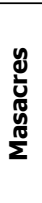 & 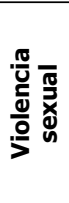 & 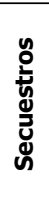 & 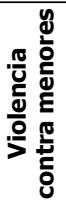 & 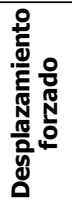 & 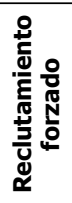 \\
\hline El Salvador & $\bullet$ & & $\cdot$ & $\cdot$ & & & & & \\
\hline Guatemala & $\bullet$ & $\bullet$ & & & & $\bullet$ & & $\cdot$ & $\bullet$ \\
\hline Brasil & $\bullet$ & & $\cdot$ & & & & & & \\
\hline Sudáfrica & $\cdot$ & & • & $\cdot$ & & & & - & \\
\hline Sierra Leona & & & & $\bullet$ & & & $\cdot$ & $\cdot$ & $\cdot$ \\
\hline Perú & $\cdot$ & & $\cdot$ & $\cdot$ & $\cdot$ & $\cdot$ & $\cdot$ & & \\
\hline Ghana & $\bullet$ & & $\bullet$ & & & $\bullet$ & & & \\
\hline
\end{tabular}

Fuentes: ICTJ (2011), Herrera y Torres (2005), CRI (2006) y análisis propios de los países presentados en este trabajo.

\section{Tabla 3}

\begin{tabular}{|c|c|c|c|c|c|c|c|c|}
\hline \multicolumn{9}{|c|}{ PRINCIPALES ACTOS DOCUMENTADOS ATRIBUIDOS A LAS FUERZAS DE SEGURIDAD } \\
\hline $\begin{array}{l}\text { El } \\
\text { Salvador }\end{array}$ & Desapariciones & \begin{tabular}{|l} 
Violencia \\
ejercida \\
contra \\
opositores \\
políticos \\
\end{tabular} & & & & & & \\
\hline Guatemala & $\begin{array}{l}\text { Desapariciones } \\
\text { contra el } \\
\text { pueblo maya }\end{array}$ & $\begin{array}{l}\text { Actos de } \\
\text { genocidio } \\
\text { de las } \\
\text { fuerzas } \\
\text { armadas } \\
\text { contra el } \\
\text { pueblo } \\
\text { maya } \\
\end{array}$ & $\begin{array}{l}\text { Exterminio } \\
\text { contra el } \\
\text { pueblo maya }\end{array}$ & $\begin{array}{l}\text { Ejecuciones } \\
\text { contra el } \\
\text { pueblo maya }\end{array}$ & $\begin{array}{l}\text { Secuestros } \\
\text { contra el } \\
\text { pueblo } \\
\text { maya }\end{array}$ & $\begin{array}{l}\text { Actos de } \\
\text { violencia de } \\
\text { grupos de } \\
\text { poder en asocio } \\
\text { con fuerzas } \\
\text { gubernamentales }\end{array}$ & \begin{tabular}{|l|} 
Desplazamiento \\
forzado
\end{tabular} & $\begin{array}{l}\text { Reasentamientos } \\
\text { militarizados }\end{array}$ \\
\hline Brasil & Desapariciones & Asesinatos & Tortura & $\begin{array}{l}\text { Detención } \\
\text { arbitraria }\end{array}$ & $\begin{array}{l}\text { Privación } \\
\text { de su } \\
\text { actividad } \\
\text { laboral } \\
\end{array}$ & Exilio & & \\
\hline Sudáfrica & Desapariciones & $\begin{array}{l}\text { Asesinatos } \\
\text { dentro y } \\
\text { fuera del } \\
\text { país }\end{array}$ & Tortura & $\begin{array}{l}\text { Incursiones en } \\
\text { países vecinos }\end{array}$ & & & & \\
\hline $\begin{array}{l}\text { Sierra } \\
\text { Leona }\end{array}$ & & Asesinatos & $\begin{array}{l}\text { Amputaciones } \\
\text { de miembros }\end{array}$ & $\begin{array}{l}\text { Desplazamiento } \\
\text { forzado }\end{array}$ & Secuestros & $\begin{array}{l}\text { Detenciones } \\
\text { arbitrarias }\end{array}$ & & \\
\hline Perú & Desapariciones & Asesinatos & Tortura & $\begin{array}{l}\text { Violación de } \\
\text { garantías } \\
\text { procesales }\end{array}$ & & & & \\
\hline Ghana & Desapariciones & Asesinatos & Tortura & $\begin{array}{l}\text { Detenciones } \\
\text { arbitrarias }\end{array}$ & & & & \\
\hline
\end{tabular}

Fuentes: ICTJ (2011), Herrera y Torres (2005), CRI (2006) y análisis propios de los países presentados en este trabajo.

\section{Cuadro 1: Miembros, personal, presupuesto y audiencias}

\begin{tabular}{|l|l|l|l|l|}
\hline \multicolumn{1}{|c|}{ País } & \multicolumn{1}{|c|}{ Miembros } & \multicolumn{1}{c|}{ Personal } & \multicolumn{1}{c|}{ Presupuesto US \$ } & $\begin{array}{c}\text { Audiencias } \\
\text { públicas }\end{array}$ \\
\hline El Salvador & $\begin{array}{l}3 \text { miembros } \\
\text { (todos extranjeros })\end{array}$ & $15-45$ & 2,5 millones & No \\
\hline Guatemala & $\begin{array}{l}3 \text { miembros } \\
(2 \text { nacionales, } 1 \text { extranjero) }\end{array}$ & 200 apróx. & 9,5 millones & No \\
\hline Brasil & N/D & N/D & N/D & \\
\hline Sudáfrica & $\begin{array}{l}17 \text { miembros } \\
\text { (todos nacionales })\end{array}$ & 300 & $\begin{array}{l}18 \text { millones anuales durante } \\
\text { el periodo de mayor } \\
\text { funcionamiento. }\end{array}$ & Sí \\
\hline
\end{tabular}




\begin{tabular}{|l|l|l|l|l|}
\hline \multicolumn{1}{|c|}{ País } & \multicolumn{1}{|c|}{ Miembros } & Personal & \multicolumn{1}{c|}{ Presupuesto US \$ } & $\begin{array}{c}\text { Audiencias } \\
\text { públicas }\end{array}$ \\
\hline $\begin{array}{l}\text { Sierra } \\
\text { Leona }\end{array}$ & $\begin{array}{l}7 \text { (4 nacionales y } 3 \\
\text { extranjeros }\end{array}$ & $\begin{array}{l}28 \text { fijos, } 70 \\
\text { en total }\end{array}$ & $\begin{array}{l}\text { Al comienzo, } 10 \text { millones de } \\
\text { dólares, se redujo a 6,6 millones } \\
\text { de dólares }\end{array}$ & Sí \\
\hline Perú & $\begin{array}{l}13 \text { Miembros (todos } \\
\text { nacionales) }\end{array}$ & 10 millones de dólares & Sí \\
\hline Ghana & $\begin{array}{l}9 \text { miembros (todos } \\
\text { nacionales) }\end{array}$ & $\begin{array}{l}115, \text { luego se } \\
\text { redujo a } 80\end{array}$ & $\begin{array}{l}\text { Al comienzo } 5 \text { millones de } \\
\text { dólares, se redujo a 1,5 millones } \\
\text { de dólares. }\end{array}$ & Sí \\
\hline
\end{tabular}

Fuentes: ICTJ (2011), Herrera y Torres (2005), CRI (2006) y análisis propios de los países presentados en este trabajo.

Mientras tanto, la comisión Sudafricana contaba con un mandato legal muy detallado que incluía distintos tipos de crímenes en su objeto de investigación.

Los casos de Guatemala y El Salvador ilustran como pocos la importancia y posibilidad de pactos de paz sustantivos que redefinan el conjunto del Estado y de la sociedad. Por supuesto que se dan en circunstancias históricas particulares e irrepetibles, tanto por el contexto internacional como por la vigencia de un tránsito desde dictaduras a regímenes liberales. Pero ello no le resta importancia a las lecciones sobre la prevalencia de la solución negociada y la posibilidad de recomposición del poder o sobre la conveniencia del concurso internacional y de la participación ciudadana en los procesos, y en fin sobre la urgencia de pensar en detalle el posconflicto y tener un horizonte en el reconocimiento de los derechos humanos, su realización y su exigibilidad.

En Latinoamérica solo Brasil y El Salvador mantienen vigentes amnistías que benefician a los denominados victimarios. La mayoría de países las han revertido o han decidido, a través de procedimientos judiciales, no aplicarlas. En Argentina, Chile y Perú, las amnistías fueron declaradas inaplicables mediante decisiones legislativas o judiciales.

Los ejemplos de El Salvador, Sudáfrica y Guatemala y algunos de los casos estudiados por Priscila Hayner (2001) en su libro Unspekable Truths, permiten concluir que los factores que dan forma a esa verdad producida por una comisión de este tipo, se centran en: la naturaleza del mandato, el tiempo de duración de la comisión, la voluntad de las partes, la metodología a usar y las limitaciones de recursos. Concluye que las comisiones de la verdad pueden llegar a respaldar el logro de la justicia. De igual forma discute la posibilidad de reconciliación, sostiene que las comisiones de la verdad pueden contribuir a la reconciliación nacional, pero no en el nivel individual.

Dado que en los mandatos de la mayoría de la comisiones se evidencia una falta de poder, para estas poder influenciar en decisiones es clave establecer un programa mediante la emisión de recomendaciones en su informe final. Estas recomendaciones están destinadas a impedir la repetición de los abusos del pasado. De otro lado, se plantea que las reparaciones con frecuencia han resultado ser una parte significativa de la justicia 
de transición y no hay discusión sobre las formas en las que la búsqueda de la verdad está conectada a la reparación.

En las comisiones analizadas los objetivos eran principalmente investigar los hechos violatorios de los derechos humanos (todas las comisiones observadas ${ }^{2}$ ), superar la impunidad (El Salvador), preservar la memoria histórica (Guatemala) y esclarecer el nivel de abuso de los regímenes (Ghana). En cuanto a los hallazgos, por lo menos tres (El Salvador, Guatemala y Brasil) de las siete comisiones constataron la violación a los derechos humanos por parte de las fuerzas de seguridad del Estado. Cuatro (El Salvador, Guatemala, Brasil y Sudáfrica) recomendaron explícitamente cambios institucionales en el sector de seguridad y la depuración de las fuerzas militares y de policía. De otro lado en los informes finales de cuatro de las comisiones, se hace explicita la responsabilidad de los grupos de oposición sobre las violaciones a los derechos humanos, estos casos se evidenciaron en los informes de El Salvador, Guatemala, Perú y Sierra Leona.

\section{Conclusiones sobre comisiones de la verdad y aprendizajes para Colombia}

Como resultado del análisis realizado, así como de los documentos y autores estudiados, se puede concluir que en la gran mayoría de los informes finales de las comisiones de la verdad, independientemente de que sean oficiales o no, se recomienda algún tipo de reforma a las fuerzas de seguridad. De igual forma las siete comisiones estudiadas constatan, en mayor o menor medida, la responsabilidad de las fuerzas de seguridad en la violación de los derechos humanos, principalmente en cuanto a desapariciones, asesinatos, detenciones arbitrarias y torturas. Esta pequeña muestra, representa la tendencia de las comisiones de la verdad.

En este mismo sentido es fundamental recalcar que así como las fuerzas de seguridad han sido responsables de algunas de estas violaciones, en todos los casos los grupos de oposición -llámense grupos terroristas, guerrillas, oposición política etc. - también tienen una alta responsabilidad en las violaciones cometidas. No obstante casi siempre el foco de atención se centra en las fuerzas de seguridad estatales, por cuanto estas tenían como responsabilidad estatal defender a sus ciudadanos. Otro elemento que lleva la atención hacia las fuerzas de seguridad es el tema de la información y de las denuncias que reciben las comisiones. En este sentido en pocas ocasiones los grupos rebeldes tienen documentadas acciones delictivas y por el contrario, las fuerzas institucionales sí tienen un buen registro de sus acciones y esto se ha utilizado en muchos casos para construir los escenarios de culpabilidad de las fuerzas del Estado (Brasil).

\footnotetext{
${ }^{2}$ En Sudáfrica se amplía a analizar las causas, naturaleza y duración de las violaciones de los derechos humanos. En Sierra Leona, a identificar las causas, naturaleza y el grado de las violaciones de los derechos humanos.
} 
Siguiendo con el tema de la información en el marco de la combinación de todas las firmas de lucha, en buena parte de los casos el perpetrador es difuso, no porta uniforme, no es fácil de identificar, de manera que las víctimas tienen dificultad al denunciar a estos grupos al margen de la ley. De otro lado se evidencia que muchas organizaciones (civiles) al servicio de esos grupos opositores al margen de la ley, son metodológicamente organizadas y se han encargado de documentar falsamente la historia de las supuestas violaciones a los derechos humanos por parte de las fuerzas de seguridad. Esto ha tenido mucho peso para las comisiones al momento de obtener documentos, evidencias, constancias, testimonios y relatos que son las fuentes en las que basan sus investigaciones.

En el caso colombiano la versión más cercana de una comisión de la verdad es la que se creó para investigar los hechos del Palacio de Justicia en el 2005. Esta comisión careció de atribuciones jurisdiccionales y de facultades para derivar responsabilidades individuales de cualquier índole, por lo que su mandato fue esencialmente ético, histórico y académico, enmarcado en los valores que orientan el Estado de Derecho, el ordenamiento constitucional y la normatividad internacional vinculante para Colombia, tanto desde la perspectiva del derecho internacional de los derechos humanos como del DIH y el derecho penal internacional, marco propio y característico del trabajo de las comisiones de la verdad -aplicable integralmente al caso colombiano, ya que sus normas se refieren tanto a las obligaciones estatales como a las del grupo de actores armados irregulares.

Es de esta forma que la futura comisión de la verdad para investigar el conflicto armado colombiano tendrá como ventaja el aprendizaje internacional de más de tres décadas de conocimiento y más de 30 comisiones de la verdad creadas a lo largo y ancho del planeta. Este camino recorrido por la experiencia internacional también permite tener unos estándares internacionales bastante amplios sobre cómo debe ser una comisión de la verdad, lo cual puede facilitar o complicarle la tarea al Estado colombiano a la hora de determinar los pormenores de la futura comisión.

La posible comisión se podría llamar Comisión de la Verdad y Reconciliación para Colombia (CVRC). Tendría como uno de sus principales objetivos esclarecer, en la medida de lo posible, los hechos relativos a las violaciones de derechos humanos y las infracciones al derecho internacional humanitario ocurridas dentro del conflicto armado interno. El periodo a investigar por la CVRC podría ser de 1964 a 2012, un periodo de tiempo bastante amplio pero que satisface en buena parte, la necesidad de verdad de todas las víctimas. Según la tendencia internacional, el tiempo promedio de duración de una comisión es de uno a tres años, de manera que en este caso y teniendo en cuenta la magnitud del conflicto colombiano pero también la urgencia de verdad, la comisión podría tener un tiempo de operación de tres años a partir de su creación, la cual ya está contemplada en el acto legislativo 01 de 2012 o Marco Jurídico para la Paz, en su artículo primero inciso tercero. 
No obstante la creación de la comisión de la verdad, en cuanto a su conformación y mandato, seguramente será uno de los acuerdos a los que se llegue entre el gobierno y la guerrilla de las Farc como una necesidad lógica y como una herramienta más que le permita al país conocer la verdad sobre estas décadas de conflicto. El mandato debe ser lo suficientemente explícito para reducir en lo posible, el tema de la interpretación. De igual manera debe tener en cuenta que tras de cerca de 50 años, existe una multiplicidad de victimas pero también de victimarios, por lo que el proceso no va a ser nada fácil.

Otro elemento fundamental es que la CVRC debe constituirse teniendo en cuenta las experiencias internacionales pero basándose principalmente en la realidad, en las características y en las posibilidades del contexto colombiano. El mandato debe procurar una investigación comprehensiva y podría tener una composición mixta entre nacionales, con apoyo de un pequeño componente internacional.

En este sentido se requiere que su conformación represente en la medida de lo posible, a la sociedad colombiana, inclusive a las partes en confrontación, tal que su conformación genere tranquilidad y consenso, así como la fe en que la investigación va a satisfacer todas las necesidades de verdad del país, sin distinción del sector al que se represente. En este mismo sentido y continuando con la tendencia de las conversaciones de La Habana, dentro de la CVRC se debería lograr que un miembro de la fuerza pública y uno de la guerrilla hagan parte de su composición.

El objetivo final de la CVRC debe ser facilitarle al país la comprensión del alcance y las pautas de las violaciones cometidas en el pasado. La labor de la comisión debe ayudar a nuestra sociedad a comprender y reconocer una historia que todavía no está escrita, procurando dar a conocer públicamente los testimonios y las historias de todas las víctimas ${ }^{3}$, así como servir de método preventivo para evitar la repetición de estos luctuosos hechos. Sin embargo, como resultado de este estudio, se plantea que el alcance de la CVRC llegue solo hasta la redacción de los informes en los que las recomendaciones no puedan sugerir: 1.) la individualización de los responsables; 2.) recomendar acciones penales o investigaciones judiciales; 3.) permitir que entes judiciales empleen el contenido de los informes para la apertura de procesos.

Lo anterior teniendo en cuenta que la CVRC será parte del resultado de unos acuerdos de paz que buscan acabar con el conflicto armado interno en el marco de la justicia transicional, que en el caso colombiano incluirá toda la batería de herramientas e instrumentos del modelo de justicia transicional que Colombia viene desarrollando

\footnotetext{
${ }^{3}$ Ley 1448 de 2011 . Artículo $3^{\circ}$. VÍCTIMAS. Se consideran víctimas, para los efectos de esta ley, aquellas personas que individual o colectivamente hayan sufrido un daño por hechos ocurridos a partir del $1^{\circ}$ de enero de 1985, como consecuencia de infracciones al Derecho Internacional Humanitario o de violaciones graves y manifiestas a las normas internacionales de Derechos Humanos, ocurridas con ocasión del conflicto armado interno.
} 
desde hace más de 10 años incluyendo también lo que se determine en el marco jurídico para la paz, el cual tendrá el grueso de la responsabilidad del tratamiento jurídico diferenciado para los distintos grupos armados al margen de la ley que hayan hecho parte en el conflicto armado interno y también los agentes del Estado, en relación con su participación en el mismo.

La CVRC debe constituirse en una de las principales herramientas para la construcción de la memoria histórica de nuestro país, sin embargo, se debe llegar a un consenso sobre cuál debería ser su verdadero objetivo así como ser conscientes de sus limitaciones e implicaciones. Si la idea del país es superar el conflicto a través de un proceso de construcción de paz que dignifique los principios de verdad, justicia, reparación y garantías de no repetición una vez firmados unos acuerdos de paz, entonces deberíamos apostarle a que la comisión de la verdad proporcione insumos para iniciar un proceso de reconciliación entre todos los que de una u otra forma han estado afectados, involucrados o tuvieron responsabilidad en el conflicto.

\section{Referencias}

Amnistía Internacional. (2009). Ghana: A seven point human rights agenda for the new government. Recuperado de https://www.amnesty.org/es/documents/do cument/?indexNumber=AFR28\%2Foo1\%2F2009\&language $=$ en

Amnistía Internacional. (2011). Informe 2011 Amnistía Internacional: El estado de los Derechos Humanos en el mundo. Madrid: Amnistía Internacional.

Amnistía Internacional. (s.f.). Comisiones de la verdad. Recuperado de http://www. amnesty.org/es/international-justice/issues/truth-commissions

Arquidiócesis de Sao Pablo y el Consejo Mundial de Iglesias. (1985). Nunca Mais. Brasil: Arquidiócesis de Sao Pablo y el Consejo Mundial de Iglesias.

Asociación Internacional de Fomento, AIF. (2007, febrero). Sierra Leona: Recuperación tras años de conflicto. Recuperado de http://www.bancomundial.org/aif

Buergenthal, T., \& Figueredo, R. (1993). De la Locura a la Esperanza: la guerra de los Doce Años en El Salvador. Comisión de la Verdad para El Salvador. El Salvador: Naciones Unidas. Recuperado de http://www.derechoshumanos.net/ lesahumanidad/informes/elsalvador/Introduccion-Mandato-Cronologia.pdf

Comisión de la Verdad y la Reconciliación del Perú. (2003). Informe final. Comisiones de la verdad. Perú. Recuperado de http://www.cverdad.org.pe

Comisión de Esclarecimiento Histórico, CEH (1994, junio 23). Acuerdo sobre el establecimiento de la Comisión para el Esclarecimiento Histórico de las violaciones a 
los derechos humanos y los hechos de violencia que han causado sufrimientos a la población guatemalteca. Oslo: CEH. Recuperado de http://www.guatemalaun. org/bin/documents/Acuerdo\%2oComisi\%C3\%B3n\%2oEsclarecimiento\%20 Hist\%C3\%B3rico.pdf

Congreso de la República. (2012). Acto Legislativo o1 de 2012. Bogotá: Secretaría del Senado de la República.

Cuya, E. (1996). Las Comisiones de la Verdad en América Latina. Revista Memoria, III. Recuperado de http://www.derechos.org/koaga/iii/1/cuya.html

De Gamboa, C., \& Mejía, J. A. (2010). El caso peruano: un análisis del modelo transicional en el postconflicto. En De Gamboa, C. (Ed.) El tránsito hacia la paz: de las herramientas nacionales a las locales, estrategias de la transición en cinco países y en tres ciudades colombianas (pp . ). Bogotá: Universidad del Rosario, GTZ.

Escuela de paz de Barcelona. (2001). Acompañamiento internacional de contextos posbélicos o pos acuerdos. África Central y Grandes Lagos. Recuperado de http:// escolapau.uab.cat/img/programas/rehabilitacion/paises/o6sier.pdf

Escuela de paz de Barcelona. (2003, enero - marzo). Barómetro Numero 1. Recuperado de http://escolapau.uab.cat/img/programas/alerta/barometro/barometre.pdf

Escuela de paz de Barcelona. (2006). Comisión de la verdad de Sierra Leona. Recuperado de http://escolapau.uab.cat/img/programas/derecho/justicia/fichaoo6.pdf

González, E. (2011).¿Hacia dónde van las comisiones de la verdad?. En Justicia Transicional, manual para América Latina (pp. 341-357). Editor Felix Reategui. Brasilia: Comisión de Amnistía, Ministerio de Justicia; Nueva York: Centro Internacional para la Justicia Transicional, 2011.

Hayner, P. (2001). Unspeakble Truths. New York y London: Routledge. Recuperado de http://inspirasi.co/books/1411046261.pdf

Hayner, P. (2006, junio). Comisiones de la verdad: resumen esquemático. International Review of the Red Cross, (862), 1-18. Recuperado de https://www.icrc.org/spa/ assets/files/other/irrc_862_hayner.pdf

Herrera, C. J., \& Torres, S. (2005). Reconciliación y Justicia Transicional: Opciones de justicia, verdad, reparación y perdón. Papel Político, (18), 71-112. Recuperado de http://www.redalyc.org/pdf/777/77720389004.pdf

La negociación de paz en Guatemala: una agenda de desarrollo. (2007, febrero). Documentos sobre democracia y paz, 41, 78-83. 
International Center for Transitional Justice, ICTJ (2010). Brasil. Recuperado de https://www.ictj.org/es/node/75

International Center for Transitional Justice, ICTJ (2011). Justicia Transicional, manual para América Latina. Brasil: ICTJ.

International Center for Trasitional Justice, ICTJ. (2010, Abril 30) Brasil: decisión sobre ley de amnistía afecta el cumplimiento de las obligaciones con las víctimas. Bogotá.

Marchesi, A-. (2001). Las lecciones del pasado, memoria y ciudadanía en los informes 'nunca mas.' CLACSO, Consejo Latinoamericano de Ciencias Sociales. Recuperado de http://bibliotecavirtual.clacso.org.ar/clacso/becas/20101111083955/ marchesi.pdf

Ministerio de Educación (1994). Historia de El Salvador. Tomos I y II. El Salvador: Convenio Cultural México, Ministerio de Educación.

Ndemole, E. (2008, junio). Truth and Reconciliation Commissions: a comparative study of South Africa, Ghana and Sierra Leone. Tesis no publicada. European University Centre for Peace Studies. Stadtschlaining, Burg, Austria. Recuperado de http:// epu.ac.at/fileadmin/downloads/research/Migyirka.pdf

Oficina del Alto Comisionado de las Naciones Unidas para los Derechos Humanos, OACNUHD (2006). Instrumentos del Estado de Derecho para sociedades que han salido de un conflicto. Comisiones de la verdad. Nueva York y Ginebra: Naciones Unidad. Recuperado de http://www.ohchr.org/Documents/Publications/ RuleoflawTruthCommissionssp.pdf

Restrepo, M. L. (2004, enero - febrero). Memoria y consolidación democrática. Revista Javeriana, 140(701), 16-22.

Rettberg, A. (2005). Entre el perdón y el paredón: preguntas y dilemas de la justicia transicional. Bogotá: Universidad de los Andes.

Townsend, B. (2008). Conflicto y políticas de contrainsurgencia en América Latina: los casos de Colombia y Perú: 1985-1995. Monografía de grado no publicada. Pontificia Universidad Javeriana, Bogotá.

Truth and Reconciliation Commission of South Africa Report (2006) Recuperado de http://www.justice.gov.za/trc/report/finalreport/Volume\%203.pdf

United States Institute of Peace (2002a). Truth Commission: Sierra Leone. Truth commissions digital collection. Recuperado de http://www.usip.org/publications/ truth-commission-sierra-leone 
United States Institute of Peace. (2002b). Truth Commission: Ghana. Truth commissions digital collection. Recuperado de http://www.usip.org/publications/ truth-commission-ghana

Ventura, M. R. (2012). La Comisión de la Verdad y la Reconciliación (TRC) y su vínculo con la transición democrática sudafricana. México: El Colegio de México. 